\title{
The Philosophical Foundations of Psychiatry in the Ancient Greece
}

\author{
José E. Muñoz-Negro', Juan F. Mula-Ponce1, Josefa M. López-Pérez², \\ José Pablo Martínez-Barbero ${ }^{3}$, Jorge A. Cervilla ${ }^{2}$ \\ ${ }^{1}$ UGC Salud Mental Hospital Universitario San Cecilio, Servicio Andaluz de Salud, Granada, Spain \\ ${ }^{2}$ Departamento de Psiquiatría, Universidad de Granada, Granada, Spain \\ ${ }^{3}$ UGC de Radiodiagnóstico, Hospital Universitario Virgen de las Nieves, Granada, Spain \\ Email: jemunoznegro@gmail.com
}

How to cite this paper: Muñoz-Negro, J. E., Mula-Ponce, J. F., López-Pérez, J. M., Martínez-Barbero, J. P., \& Cervilla, J. A. (2018). The Philosophical Foundations of Psychiatry in the Ancient Greece. Open Journal of Philosophy, 8, 277-293. https://doi.org/10.4236/ojpp.2018.83020

Received: April 19, 2018

Accepted: May 22, 2018

Published: May 25, 2018

Copyright $\odot 2018$ by authors and Scientific Research Publishing Inc. This work is licensed under the Creative Commons Attribution International License (CC BY 4.0).

http://creativecommons.org/licenses/by/4.0/

\begin{abstract}
The object of study of Psychiatry is hybrid, that is, it is both natural and social. It combines the methods of natural Sciences and those of social Sciences. Currently, Psychiatry is the branch of Medicine where epistemological and hermeneutical conflicts are more than evident; it is the medical discipline where this debate is most intense and problematic. However, the conceptual foundations of all these debates and conflicts are already preconfigured within the framework of the Greek philosophy of the Classical period. Without knowing these conceptual foundations it is impossible to adequately clarify all these conflicting aspects. During the period of Classical Greece it was the time when the conceptual foundations and rationale of the tekné iatriké (of which Psychiatry was and is a part) were established as well as the theoretical principles of epistemological issues such as the validity of categories, the controversy between diagnostic categories and psychopathological dimensions, the approach towards both subjectivity and phenomenology, the inquiry for Psychopathology, the concept of mental health, the possibilities and limits of the scientific method in Psychiatry, the role of Psychotherapy and, naturally, some key ethical issues in mental health, such as the existence of the stigma on psychiatric disorders and all of the problems raised by the coercitive practices. To answer all of these questions, a review of the literature on this topic has been made in this paper, as well as a discussion and analysis of the key points of the epistemological and ethical debate.
\end{abstract}

\section{Keywords}

Philosophy, Psychiatry, Epistemology, Classical Greece

\section{Introduction}

Many of the current epistemological problems in contemporary Psychiatry can- 
not be solved without understanding the past. Knowledge of the philosophical and conceptual foundations established in the period of Classical Greece helps us to solve current epistemological and ethical problems. Besides, the psychiatric objectives cannot be understood correctly without knowing adequately their conceptual premises. Therefore, the knowledge of the philosophical, epistemological and historical foundations of Psychiatry is essential for the comprehension of some of the most controversial issues in contemporary Psychiatry. Some experts have mentioned that the lack of knowledge about the history of Western Civilization limits drastically among Psychiatry residents the capacity to understand not only the epistemological status of this area of knowledge but, above all, to have an adequate training (De Leon, 2013). In his General Psychopathology (Jaspers, 1913), Jaspers carried out an immense epistemological effort to understand the nature of symptoms and the psychopathology of mental illnesses, leading him to confirm that in Psychiatry there were illnesses analogous to the ordinary medical ones, which meant that they could be studied and analyzed with Natural Science methods, while other illnesses, that presented clear variations of an ordinary pattern, had to be addressed with Social Science methodology. In the same line of thought, for Berrios and others, Psychiatry is a hybrid object (Berríos, 2011) with a dual reality from both Natural Sciences and Social and Humanistic Sciences that requires a transdisciplinary approach (Van Os, 2012) and, obviously, from multiple perspectives (McHugh \& Slavney, 2001; Van Os, 2012). Psychiatry is not only Neuroscience but it also demands openness to intentional, semantic and sense aspects that cannot be studied with just neuroscientist methods (De Leon, 2014). As Berrios says, psychiatric objectives cannot be studied without understanding the conceptual systems from which they are explained. Issues such as the nature of the mental, the concepts of both health and illness, the methodological verification of the scientific method to address subjective matters, stigma, coercion, the mind-brain relationship, the moral responsibility in mental illnesses, the validity and transcultural universality of diagnoses, the inquiry for psychopathology and its contents, the right perspectives for the understanding of mental disorders and many others, have their philosophical foundations, or even occasionally their conceptualizations, in approaches already existing in Classical Greece. Knowing them is not only an act of scholarship, but it helps to understand, clarify and envisage new ways or possibilities that may lead to the awakening of Psychiatry, at present rather asleep (De Leon, 2014).

The purpose of this article is to facilitate the understanding of certain current epistemological and ethical problems, such as the ones above mentioned, as well as others existing in Psychiatry, applying the approach based on the philosophical and conceptual foundations set by Philosophy in Classical Greece. In order to achieve this aim, the article is structured as follow: a section of methods where is detailed the methodology utilized for this article, and subsequent sections explaining the main contribution of the Greek Philosophy to the conceptual basis 
of the Psychiatry. Finally, a final section of discussion and conclusions is developed.

\section{Material and Methods}

In order to achieve our aim of revisiting the philosophical past in the Classical Greece, in order to understand and to shed light over the currents perspectives and psychiatric practices, we have reviewed and summarized the existent literature on this topic using different sources such as Pubmed and some manual searching. Finally, we have provided our critical view by discussing and elucidating the connection between the Greek roots and the present epistemological problems concerning the modern and postmodern psychiatric perspectives.

\section{The Myth and Its Influence in Medicine and Psychiatry}

Since Antiquity there have been three basic approaches to the interpretation of psychic phenomena: the biological, the psychological, and the sacred (Tzeferakos \& Douzenis, 2014). The three of them have reached the present day; the first two keep on being predominant in the health sphere, while the third one stays within society, although with other forms.

The influence of myths in Medicine and Psychiatry is immense and comes up to our days, not only because in them we can find the bases that represent the transition almost without interruption towards Philosophy, but especially because the issue of the symbolic and narrative nature of the human being is preconfigured in them. Thus Freud will make use of Greek myths to explain the basic conflicts of human subjectivity, although he will do it based on 19th century mechanism and positivism. However, the explanatory force of myths to explain the intrapsychical conflicts keeps on beating very lively in postmodern culture. Far from disappearing surpassed by scientific and technical reasoning, myths still survive in today's culture as an essential element for its understanding. Paradoxically, in the era of the scientific and technical globalization, there is a boom of the mythic consciousness that coexists with scientific rationality in a similar way as myth and reality did in Classical Greece (Ivanovic-Zuvic, 2004). The metaphorical potential of myths for a deep and holistic understanding of the human being is undeniable, as was clearly shown by Carlo Gustav Jung's work. For him there was a series of mythical archetypes that belong to the collective unconscious. The difficulty to gain access and understand that mythical background would constitute a mental health problem. To prove this assertion we can focus on the work of Ramón Sarró, who recuperates this concept of mythic archetypes for the phenomenological exploration of psychosis and enables an individual approach that allows the reconstruction of the inner and meaningful world of each patient far beyond the categorical consideration of mental health.

The present validity of the myths that were already expressed in Classical Greece is not just terminological, psychological or nosological (e.g., the conflict of Oedipus or the narcissist personality disorder), but at present it also allows us 
the comprehension of phenomena such as the interest for alternative medicine, the placebo effect, the propensity to polypharmacy, the tolerance towards the recreational use of psychotropic substances, the stigma or much of the current bias against Psychiatry, mental disorders or Psychopharmacology (Bermejo Saiz, Perez Urdániz, \& Santos, 2012; Fornaro, Clementi, \& Fornaro, 2009).

In the old times of myth, drugs certainly had an ambivalent character, as they could be either beneficial or toxic alike. The search for a comprehensive healing, practiced by Asclepius' followers in temples, apart and beyond being a mere cure, persists today in the constant search of a medicine and a more holistic psychiatry which, because of its not being frequently offered, forces patients to look for alternative medical and psychiatric systems that incorporate health and disease models that have not broken away from ancient myths. The importance of the non-specific factors of the relationship patient/doctor connected with the mobilization of the placebo effect was already described by Homer, who commented how the wounded heroes treated personally by Helen of Troy evolved better and healed their wounds before otherwise (Fornaro et al., 2009). The myth-based medicine also remains in an unconscious way in certain non-rational uses of drugs as it happens to be the case of a determined polypharmacy that can only be justified as the answer to beliefs and mythical expectations existing among patients that are validated by some doctors through its use.

A somehow more bastard use of the term that draws from sophistical and skeptical roots is the one postulated by Thomas Szasz in the "Myth of the Mental Illness" (Szasz, 1961), being understood this type of illness as an arbitrary construction without objective foundation beyond the mere social utility of the concept of mental illness as a control element. Modern antipsychiatry aims at sending Psychiatry back to the myth by denying its scientific status, and so it makes a negative and pretentious use of the term "mythical" as opposed to "scientific" and as synonymous of "false, subjective and arbitrary".

During the myth period in Classical Greece, the model of predominant disease was that of devil or divinity possession. That is what appears in the literary works of Homer (La Croce, 1981). In addition to that, he will understand the body as a soma articulated by several parts. Besides, neither will he allude to a soul unified and differentiated from the body; he spoke of psyche, thymos, and noos instead (Ivanovic-Zuvic, 2004). According to Homer, Psyche has a material nature, it leaves the body when this one dies, and it keeps full existence when a man dies; Thymos is the organ of movement, both physical and emotional, and Noos is the organ of both knowledge and images. Both Thymos and Noos die when Soma does. It is now when the distinction between body, mind-brain and soul begins to get elaborated. Psyche is material and it only exists when the human being dies or loses consciousness. Thymos and Noos would be the mind as we know it today. This clear distinction of two instances within the mental, i.e. affective and cognitive, will be very important, as it will reach our present days in the comprehension and explanation of different mental disorders, including 
those of personality.

The figure of Asclepius as god of Medicine is also fundamental as an element that reveals the non-separation between Mythology, Religion and Medicine. Asclepius is the son of the god Apollo and the human nymph Coronis; he was raised by the Centaur Chiron who taught him the medical knowledge and its art. During this period the Greeks will practice a psychosomatic medicine where mental and physical symptoms shall be considered manifestations of the same disease. It appears also a moral concept of illness as punishment due to some type of guilt. This approach will later be worsened by the understanding of mental illness as a diabolic possession given the fact that in the later Platonic dualistic anthropology, dominant in a greater part of the Middle Ages, the rational soul could not get sick as it belonged to the world of ideas. In a post-myth stage, the Platonic dualism will split up body and soul and will lay the ground for an understanding of mental illness outside the body and in the realm of the demonic. These visions have reached our days in the form of stigma as well as ambivalence and sensibility towards Psychiatry and mental illness different from the ones that appear in connection with the so-called "somatic" diseases.

Far from disappearing, myths are still valid in a technological society, a clear example of which is the current mentality and interest on alternative medicines and psychiatry. The search of myths for stories about origins that somehow try to give unity and meaning to the human being seems more necessary than ever. The current division between rationality and emotions, between "noos" and "thymos", was already configured in Classical times. The search for the unity of the human being, understood as a psychosomatic unit, as well as the idea of the "sacred" character of both Medicine and Psychiatry, as professions that touch the most intimate and integral part of the human being, began in the mythical period and, as such, have reached our days.

\section{The Pre-Socratics and the Human Being as Physis}

During Antiquity there was no distinction between Medicine and Philosophy. Both disciplines were thought of jointly and practiced by the same people. Nor there was a separation between Medicine and Psychiatry, something that, on the other hand, will appear much later. With the first Greek philosophers new concepts do appear and those concepts will long remain in Western thought and will open new ways quite different from those of the myth, although, as we have seen, the myth will endure through time under philosophical and scientific-technical rationale. The concept of Nature (Physis) will mark "a before" and "an after" (a turning point) in the history of Philosophy and Science. The disease will be understood since then, not as something arbitrary pertaining to the world of gods and chance and only knowable through stories and metaphors, but as the alteration of a universal substance that can be known through "logos", i.e. through human reason. Physis means to be born, to sprout; it is the universal substance, the principle of what is permanent and what is changing and is defined 
by its necessity. Thales of Miletus will establish the existence of universals that transcend the particular nature of things. The ideas of universal and particular appear: a universal substance consisting of air, earth and fire as originating elements that give rise to particular objects with a unique nature. Heraclitus and Parmenides will wonder about the essence of that universal substance, especially about what does not change in it. Heraclitus maintained that the very nature of life is flux, is change, so this essence would be in change, while for Parmenides the ultimate principle of the world, a real being, is timeless, immobile, immutable, permanent, so the essence of Being is being permanent (La Croce, 1981). Parmenides conceived the ultimate existence as permanent unchanging being, and Heraclitus as ever changing flow or process. Other pre-Socratics, such as Anaximander, Anaximenes, Empedocles or Democritus, will explain Physis as a reality that can be studied as something made of physical elements. For Empedocles man is a product of Cosmos, made of the same substance and subject to the same laws (Kirk \& Raven, 1981). On the other hand, the atomist theory of Democritus will open the way to the physicalist and biologicist currents of thought, and later to empiricism, the associative psychology and behaviorism. Democritus stated that the differences and properties of bodies were established according to the geometric and mathematical relationships of the atoms that composed them. He also explained pleasure in physical and mechanical terms as the result of the movements of the atoms that make up the soul, thus opening way for a mechanistic and biologicist understanding of subjective experiences.

This type of thinking based on Universals and Particulars (Plato viewed Universals as Ideas or Forms that exist outside of us in some higher, intellectual realm. While real things or Particulars here on earth are subject to change, the Universal Ideas always remain the same and are eternal), will later enable the emergence of psychiatric diagnoses based on categories, establishing the controversy of permanent relevance on whether these categories (Universals) actually respond to the existing nature or are fundamentally social conventions. The debate between categories and dimensions already incorporated into the DSM-5 (Barch et al., 2013) reflects unresolved issues about the validity of psychiatric diagnoses as hybrid, natural and social objects needing biological, psychological and social correlates that function as external criteria of veracity. Categories understood as Universal objects would be explained in turn by some other more basic elements underlying them, such as the psychopathological dimensions that keep an epistemological analogy with the basic elements that made up the universal substance (Air, Water, Earth, Fire) in the case of Thales of Miletus. The idea, empirically verified, of the existence of a continuum of psychosis distributed throughout the population in general (Van Os, Hanssen, Bijl, \& Ravelli, 2000) and of the categories of psychotic mental disorder (Muñoz Negro, Ibáñez-Casas, De Portugal, \& Cervilla Ballesteros, 2015) is intellectually indebted to the positions over a nature composed of basic elements that are always present to form different particular substances. 
For Alcmaeon of Croton a disease will be just a loss of balance between the forces that make up Physis. It appears then a correspondence between Reason (Logos) and Nature (Physis), and so the second one (Physis) can be known and studied from the first one. It arises then the need to study the physis of the human being (Physiology) and its alterations (Physiopathology). Thus the human being will be placed in front of a Nature that he can get to know as he is in turn part of that same Nature. Thus the subjective can also be studied as a natural entity. All the issues inherent in the objective knowledge of the subjective nature of the human being are thus opened. The unresolved tension between the objective and the subjective (Berrios, 1989; Hueso Holgado \& Cuervo Díaz, 2013), is yet another of the fundamental epistemological problems in Psychiatry, which has swung between the need to explain the subjective in an objective way and the need to understand the subject as a personal experience qualitatively irreplaceable and different in itself as far as it is particular substance.

Later on, Plato and Aristotle, respectively, will establish the philosophical foundations of both idealism and realism, which will be the fundamental coordinates of the psychiatric epistemological debate. Objectivism and Subjectivism, which result from both the Platonic and Aristotelian approaches, will be the foundations of both Kraepelin's biologicism and Freud's psychoenvironmentalism. To this schism of Psychiatry into two different models Karl Jaspers will intend to give an answer (Jaspers, 1913). About a hundred years ago, Karl Jaspers recovered the dispute between explaining and understanding, in order to facilitate a general psychopathology capable to respond to the construct of medical illness as well as to the variants of normality that appear as vital problems (De Leon, 2015). The most positivist current will result in the movement of Medicine based on evidence, and attempts to recover the subjective and particular together with the biological and objective will take shape in the current interest in personalized or patient-centered medicine (Mezzich, 2007). In addition, during this period (9th-8th century B.C.) it will also appear the concept of "tekné" or "techné" as a practical knowledge that can be transmitted, taught and used to modify Nature. From that moment on, Medicine will not only be a sacred art but it will never cease to be a technique practiced by specialists. In parallel, it does appear the philosophy of science, which answers the question about what we can know and by what means.

Nothing will be the same again after the appearance of the concepts of Nature (Physis) and Technique (tekné). Since then, the human being will be understood as a being composed by the same elements as Nature is. Medicine, as well as a sacred profession, will be viewed as a technique based on rational knowledge. Thus naturalistic explanations of behavior as well as the objective study of human subjectivity gain their way. The bases for the understanding of both Medicine and Psychiatry as natural Sciences are already laid, and so is the conflict between the mechanical paradigm and the hermeneutic paradigm in Psychiatry. 


\section{Hippocratic Medicine and Psychiatry}

Hippocrates (460-370 B.C.), a contemporary of Democritus and a bit younger than Socrates, will assume the theoretical approaches of the pre-Socratics. Hippocrates has gone down in History as someone who established the conceptual foundations of Medicine as we know it today. He introduces fundamental concepts such as sign, symptom, nosology, clinical, aetiology, therapy, diet, prognosis or anamnesis. Medicine, for his school, will be a technical knowledge (techné) aiming to become episteme. However, this episteme will not be science as we know it today, but an attempt to understand the essence of disease. The Hippocratic medicine remains within the paradigm of the philosopher physician, without solution of continuity between one discipline and the other. There will be a concordance in laws and elements between the macrocosm and the microcosm. Both the human being and the disease are nature. The doctor must understand and know the physis in order to be able to treat it. The disease will result from an imbalance in the physis either by chance or by necessity. Its physiological model will be humoral, theory that Hippocrates will take from Empedocles' 4 elements, i.e., air, water, earth and fire. The 4 humours (black bile, yellow bile, blood and phlegm) represent them in the human body, and there is also correspondence between these elements and the qualities of cold, humid, dry and hot (Pichot, 1978). The different proportions of humours in each individual result in different constitutions, thus originating a psychosomatic model. The therapy will consist of the rebalancing of that physis, although the physis can be rebalanced by itself or, by necessity, it can lead to the death of the patient. The therapy will use not only somatic treatments including drugs, but also psychotherapeutic and environmental treatments, diet, physical exercise... Psychotherapy will be a universal treatment dedicated to promoting trust and hope in the patient. A kind of rudimentary psychotherapy based on persuasion and pedagogy (Ivanovic-Zuvic, 2004).

The model of understanding mental illness in Hippocrates will be clearly organic. Mental illnesses will be somatic illnesses, caused by disturbances in humours or due to emotional causes (Ivanovic-Zuvic, 2004). This model will also give the brain a fundamental primacy, as in his Treaty of Epilepsy (Hipócrates, 1999) Hippocrates states that with the brain we dream, think and feel. In addition to that, he says that abnormalities in the brain cause mental or personality problems. The description of neuropsychiatric manifestations is quite broad: coma, convulsions, insomnia, migraine, logorrhea, delusions, depression, mania, paranoia (Pichot, 1978), anxiety (Crocq, 2015), hysteria (Novais, Araújo, \& Godinho, 2015) and others. All of them will be explained in terms of humoral disturbances affecting the brain. In particular, he will develop an organic theory of delirium as a consequence of the excessive humidity of the brain and its consequent confusional alterations (Pichot, 1978).

Together with this primacy of the brain there is a psychopathological model, which describes in detail melancholy and other disorders, and a medical model 
that emphasizes the importance of the biography of the patient and the need to empathize with him, emphasizing the particular. The aphorism "there are no illnesses but ill people" presents clear Hippocratic resonances. It is a model whose contemporary development would be the patient-centered medicine (Mezzich, 2007) that combines a rigorous biological approach with consideration of the patient's particular narrative perspective and his systemic relationships. As for Psychopathology, not only will this be descriptive but, just as the most modern psychopathology, will try to connect symptoms with alterations of a physiological or a biochemical type, in this case, humoral. Thus, melancholy will have been caused by an excess of black bile, and its treatment will consist of recovering the equilibrium between the different humors by using drugs such as green hellebore or mandrake (Pichot, 1978). Another fundamental contribution of Hippocratic medicine to psychiatry and medicine today is the moral perspective of medicine with the formulation of the principle of non-maleficence (the "do no harm" principle), fully valid today, and the conception of the clinical relationship as a triangle between patient, doctor and disease (Antoniou et al,, 2010). With Hippocrates the medical model is defined just such as we know it today, and it takes special value the patient's biography as well as the concept of lifestyle and the environmental factors (diet and regimen), considered as therapeutic factors.

Hippocrates collects the knowledge of Physis of pre-Socratics and incorporates it into Medicine. The current central concepts of medicine: aetiology, sign, symptom, treatment, clinical, prognosis, physiology and physiopathology ... have their origin in Hippocratic medicine. He will propose a naturalistic and mechanistic physiological model and will understand mental illnesses as brain diseases. The medical model in psychiatry, like the general medical model, cannot be understood without the Hippocratic medicine. At the same time, he will lay the foundations of the traditional medical model centered on the principle of non-maleficence and on medical paternalism.

\section{Socrates, Plato and the Legacy of Dualism}

Socrates (470-399 BC) is considered the first great philosopher in Ancient Greece. He was the teacher of Plato, and his fundamental contribution to the history of the philosophy of Psychiatry lies in dialectics and his method to know the truth, the Socratic Maieutics, a dialogued search of the truth in which the interlocutor ends up discovering the truth by himself. He identified soul with psyche and used the dialectical method of induction and dialogue to achieve answers and certainties. He tried to overcome through dialectic the subjectivism of the Sophists. He left no written works, but the modern, scientific and critic debate as well as the techniques of clinical interview and the current psychotherapy, especially its most constructivist and hermeneutic techniques, like the narrative psychotherapy, would not be understood today without the contribution of Socrates, which was later developed by his disciple Plato. His legacy in 
Ethics is also very important, not only for his personal testimony, but for the emphasis on the cognitive element of ethical action. Socrates emphasized the importance of knowledge of good and evil for moral responsibility. For him working correctly (virtue) was a consequence of the knowledge of the good. This preponderance of the cognitive element of moral responsibility has reached the present day (Mason, 2015) and its paradigm is still in force in modern forensic Psychiatry (Alcázar-Córcoles, Verdejo-García, \& Bouso-Saiz, 2008).

The influence of Plato (428-348 B.C.) in Medicine and Psychiatry will be enormous, since his idealistic philosophy and his dualism will decisively influence as the very foundation and the framework of understanding of any scientific activity. Plato got acquainted with the work of Hippocrates, from which he takes the Dialectics, a fundamental method not only for philosophy and pedagogy but for psychotherapy itself. This relationship with Hippocrates and his dialectics appears in his work Phaedrus (Platón, 2003) especially in his Psycagogy, as the art of persuading the sick. Currently many interview techniques or psychotherapeutic techniques assume the philosophical foundations of Psycagogy as a starting point. This is manifest in the case of interview techniques such as the motivational one and it is a factor common to virtually all psychotherapies. The importance of his philosophy lies mainly in his dualistic anthropology and the idea of innate knowledge. Plato represents, largely due to his idealism, a major scientific setback compared with Hippocrates, clearly characterized by observation (Pichot, 1978). In his dualistic model, the soul has two parts: one rational, immortal and divine, seated in the brain but, as it is divine and pertaining to the world of ideas, it cannot get sick; and another part, that is irrational and made up of two souls, one impulsive and courageous, focused on conquering honour and glory and located in the thorax, and the other one, passionate and appetitive, located in the belly and oriented to pleasure. The rational soul prevails and must direct the other two, as a charioteer (auriga) steers his quadriga. It is a model of hierarchical and locating psychism (Pichot, 1978) that keeps a certain analogy with the Freudian topical of Ego, Super-Ego and Ono. When the rational soul loses control over the irrational soul and, at the same time, the Hyppocratic humors act on it, then Psychopathology appears: melancholy, mania and dementia. There is also for him a kind of divine, prophetic madness that affects the rational soul, but that is a kind of state of grace caused by Apollo, Dionysus or the Muses.

The consequence of this dualistic hierarchy will be the distinction between two types of psychopathology, one "divine or artistic" type, that will not be properly an illness and that will open the way to a kind of romantic vision of madness, and another of an inferior type, irrational, destined to suffer stigma and that will end up falling in the scope of the diabolical possession during the Middle Ages. In addition, the brain will be seen only as the seat of the rational soul with the consequences that this will imply in the future, consequences that will be accentuated with the Cartesian dualism of a split between soul and body, objective and subjective, sciences and humanities, Psychoanalysis and Neuros- 
cience. Innatism and its concept of ideas as a form will also influence Psychiatry through a connecting thread that leads us to Kant and Nosology based on the Kantian faculties of affective (volitional), psychotic (reason) and personality (emotion) disorders and, later on, to Jaspers and his Psychopathology that will distinguish between the form of a symptom, understood as its impersonal essence, and the content, understood as the concrete substance of the symptom. Without Plato and his subsequent influence it would not be understood the predominant nosological model in Psychiatry, that of mental disorders taken as categories that, due to the Idealistic and Platonic influence, tend to be considered by clinicians as existing in themselves, as essential.

Present day science is the daughter of the Cartesian dualism of Platonic inspiration in which the body is "res extensa" which can be investigated through Science. The price of a science based on these premises will be the cleavage between the objective and the subjective and the subsequent attempts to regain access to subjectivity without turning it into a body of the physical world. European phenomenology will constitute an attempt to gain access and rebuild the subjective world of the patient through empathy and intuition beyond the mere description.

Socrates, besides being Plato's teacher, will leave us Maieutics (maieutiké) as a way to access the truth that is at the base of the clinical interview, the therapeutic relationship and psychotherapies similar to the ones based on modern constructivism. His rationalist way of understanding ethics, based on the cognitive element, still persists in the forensic psychiatric model. His disciple Plato will be decisive in the history of science because the influence of his dualism will reach our days, both in nosology (a branch of medicine that deals with classification of diseases) and in the explanation and the duality of the mind-brain relationship. Dualism and idealism will later enable a moral judgment of mental illness considered as a diabolical possession that still lasts in the form of a stigma.

\section{Aristotle and the Long Way to the Empirical Science}

Aristotle (384-322 B.C.) decisively influenced the Thomistic philosophy and Empiricism, and its significant impact on epistemology and ethics will come until day. According to Pichot, Aristotle presents a model of psychism which in turn is hierarchical, anatomical and physiological-humoral (Pichot, 1978). Being the son of man who was a doctor and a great biologist, Aristotle became well known for his skills of observation and ability to describe biological phenomena and so he has left us good psychopathological descriptions such as that of the bipolar spectrum (Pies, 2007). In this sense he was an early precursor to the descriptive psychopathology of the nineteenth century, presenting psychopathology as a description of mental symptoms understood as medical symptoms. For him a mental illness will just be a physical illness, so his epistemological assumptions or premises will serve as a basis for biological psychiatry. His thought was both inductive and teleological, based on the observation of reality and going 
back to the causes. The body will be organized in successive and hierarchical levels: from elements to tissues, from these to organs, from organs to their functions, but this body potentially would have no life if it were not for the soul. This soul is unitary, unlike the Platonic soul, and it is intimately linked to a body, "just as sight and eyes are linked to each other". Soul and body are inseparable in practice, and they are born and die together. The soul will be free, thus in Aristotle there is in that sense no psychic determinism, which will later open the way to existentialist schools in Psychiatry (Dramisino, 2013). In addition to free, the soul (psyche) is complementary to the body (soma), and so any change in the soul will influence the body and vice versa. Aristotle's conception of the human being is psychosomatic and unitary. The soul gives shape to the body. This soul has functions that are hierarchical, so each function implies the previous one but not the following one, and in parallel these functions also give a hierarchy to the living creatures. Thus there is one vegetative function that is in charge of nourishing and that would be unique to define vegetables exclusively, one sensory function in charge of perceiving, in fact present in animals but not in plants, and finally the functions of the rational soul (prudence, wisdom, intelligence and memory) and some irrational ones (temperance, justice and courage). In the hierarchical model, right in the highest level it is intelligence what figures, of which there are two types: a passive one, potentially linked to the body, and another one of transcendent dimension, pure act, which is eternal and immortal. It is the one that produces thoughts and it cannot get ill (Pichot, 1978).

In its anatomical model there is a setback, because the soul resides in the heart, not in the brain. Aristotle is a follower of the humoral theory, and in it humours carry both heat and cold. For Aristotle he heart was the organ of heat, and the brain cooled it, and in that process vapours were formed. From that vision, neurotic disorders were considered as "vaporours ailments" (Pichot, 1978) and were considered just a result of a humoral disequilibrium in physical or mechanical sense. This mechanism will arrive into dynamic Psychiatry that in turn shall conceive psychism as the result of equilibrium or disequilibrium of instinctual forces (Lear, 2014).

Aristotle is an opponent to Innatism (the mind is not a "blank slate" at birth), as he defends that all that is in our understanding comes from our senses, and he also supports the idea of "tabula rasa" (Aristóteles, 2014). This vision, together with his teleology, the hierarchy of his psychic model and Hylomorphism, that inseparably unites matter and form, would underlie a Psychiatry based on symptoms and not mainly on diagnostic categories. According to this model doctors are required to start from the symptoms and later on, according to a hierarchical model, to look for intermediate endophenotypes and finally one would reach the causes in order to find natural classes understood as disorders. This view is particularly interesting because the validity of diagnostic categories is probably the most important epistemological problem that the current Psychiatry presents nowadays. 
His influence on Psychology and Psychotherapy has been transmitted in modern personality models as well as in cognitive-behavioral psychology through empiricism and associationist psychology. He was also a precursor to the Freudian concept of catharsis and its role in psychotherapy (Gustavo Figueroa, 2014; Lyketsos, 1980; Turri, 2015).

Aristotle's influence has reached our days especially in the approach to mental health Ethics, as the prudential deliberative model based on his Nicomachean Ethics (Aristóteles, 2001). This approach has clear medical resonances and was raised from the method by which clinicians came to formulate diagnosis. The Aristotelian "Phronesis" (prudence or practical wisdom capable of avoiding extremes) is a debtor of the concept of krasis or equilibrium among the Hippocratic humours.

Like Plato's, the influence of Aristotle in medicine and psychiatry will be enormous. He gave preeminence to knowledge based on observation, opening the way to Empiricism and positive Science. He combined inductivism and teleologism, the conceptual premises of associationist psychology and later behavioral psychology. His model was hierarchical, physiological and humoral and therefore mechanistic, understanding psychopathology as the result of a humoral imbalance. His influence will also reach our days in medical ethics, both in deliberative models and in the ethics of virtue.

\section{Discussion and Conclusions}

Paradoxically and far from what it can be thought, the influence of myths is still very important in our days. Not only that. Its growing influence seems to go hand in hand with the technological imperative and the uprooting caused by technological development. Myths are a promise of returning to the origins, and the human psyche seems to harbor nostalgia of an origin and a Golden Age that we cannot ignore if we want to understand the deep motivations that move the human being. The nostalgia of a lost world seems to mark the contemporary conscience in the form of rites and a mythical, magical and religious sense that permanently seeks ways to actualize itself. A psychiatry attentive to the postmodern discontents of Civilization cannot ignore this fact. Psychopathology evolves with culture and the diagnostic categories do not cease to be groups of symptoms configured clinically and susceptible of being valued empirically. In contrast to its technological deficit, mythical medicine managed to maintain an anthropology and a unified vision of the human being consistent with a medicine that was a sacred practice.

But the human being does not need just myths; he also needs a rational knowledge of things and technology that helps him solve problems, in this case problems related to his mental health. The emergence of the concept of physis was a decisive step in medical and psychiatric knowledge conceived as a natural science but, at the same time, it introduced the possibility of biological reductionism and the alienation of the human under the scientific-technical discourse. 
With the pre-Socratic philosophers mental illness could be explained as an imbalance of the primordial elements that make up Nature; thus it is beginning to be possible to objectively explain the Subject. For Democritus the human being is made of the same atoms that form the rest of nature. And so, physiology, the science that studies the alterations of Physis, appears.

Hippocrates will shape the current medical model from which Psychiatry will emerge, a mechanistic model that will conceive the disease as an imbalance of the elements that form Physis; in this case the mechanistic model will be humoral and its influence will be long and lasting. A mental illness will be just a disease of the brain. The natural will become a moral norm and whatever is alien to nature will become deviant or sick. In the causes and treatments Hippocrates incorporated psychotherapeutic and environmental elements that will be integrated into the medical model in the future as a bio-psycho-social model. In the field of medical ethics the validity of the principle of non-maleficence continues to be a key element of modern bioethics, and the influence of medical paternalism continues today in all ethical conflicts related to autonomy and coercion.

The therapeutic relationship and the constructivist vision of modern psychotherapy would hardly be understood without the search for the truth of Socratic Maieutics. His vision of morality as a problem of the knowledge of what is evil, continues to permeate our legal and forensic system, although this vision is increasingly problematic due to the emergence of the affective and emotional element in the postmodern society, as it has been demonstrated by Neuroscience. However, the most current and pressing epistemological and ethical issues have to do with the discussion about the concept of mental health, the limits of the pathological, the psychiatrization of everyday life, the stigma of psychiatric disorders, the validity of diagnostic categories and the divergence between the mechanical and the hermeneutic models of disease. We can hardly understand all of them without the tension between rationalism and empiricism introduced by Plato and Aristotle in Western thought. The modern philosophy of the mind is not understood without their contribution, nor can be understood the tension between the psychiatry more focused on the empirical, measurable and biological aspects of human behaviour and that psychiatry more focused on the qualitative and hermeneutical aspects such as psychoanalysis and others.

The influence of Platonic dualism and idealism has been very profound in Psychiatry, especially in the construction of a categorical diagnostic model that seems to configure both medical thought and language by attributing ontological properties to entities that are nothing but universals. Although useful, that model has been overwhelmed by a more Aristotelian one where nature is a creative and hierarchical continuum, which is at the base of dimensional and evolutionary thinking. In this sense, the contribution of empiricism is at the base of the scientific method of modern psychiatry, a scientific method whose application must be carried out without prejudice to the reduction of the human being to a mere biological mechanism. Thus, more important than the epistemological questions that start from Plato and Aristotle are those of an ethical nature. Dualism 
devalued the body with connotations of impurity and deified the soul, a rational soul that could not get sick. This opened the way to the moral consideration of mental illness whose most extreme manifestation was the diabolical possession that still persists in the form of a stigma associated with mental illness.

Finally, it can be said that the knowledge of the philosophical past of Psychiatry is much more than just erudition; it has a practical meaning. It enables us to establish new scientific hypotheses as well as to adequately understand both the findings of the neurosciences and the preconceptions and the premises on which they are based. At the same time it enables us to properly understand the psychic world of the patient. It makes us better scientists and better doctors.

\section{Acknowledgements}

We would like to thank Mr. José Antonio Martínez López, Professor of English Philology and Licentiate in Classical Philology for his selfless and enthusiastic support in the writing of this manuscript.

\section{References}

Alcázar-Córcoles, M. A., Verdejo-García, A., \& Bouso-Saiz, J. C. (2008). Forensic Neuropsychology at the Challenge of the Relationship between Cognition and Emotion in Psychopathy [La neuropsicología forense ante el reto de la relación entre cognición y emoción en la psicopatía]. Revista de Neurologia, 47, 607-612.

https://www.scopus.com/inward/record.uri?eid=2-s2.0-57349172897\&partnerID=40\& $\underline{\mathrm{md} 5=\mathrm{ab} 7 \mathrm{~b} 4 \mathrm{~b} 17 \mathrm{f} 676 \mathrm{~b} 5 \mathrm{cad} 51 \mathrm{a} 113 \mathrm{~d} 4 \mathrm{~b} 02 \mathrm{~b} 67 \mathrm{f}}$

Antoniou, S. A., Antoniou, G. A., Granderath, F. A., Mavroforou, A., Giannoukas, A. D., \& Antoniou, A. I. (2010). Reflections of the Hippocratic Oath in Modern Medicine. World Journal of Surgery, 34, 3075-3079. https://doi.org/10.1007/s00268-010-0604-3

Aristóteles (2001). Ética a Nicómaco. Introducción, Traducción y Notas de José Luis Calvo Martínez. Madrid: Alianza Editorial.

Aristóteles (2014). Acerca del alma. Madrid: Gredos.

Barch, D. M., Bustillo, J., Gaebel, W., Gur, R., Heckers, S., Malaspina, D., Carpenter, W., et al. (2013). Logic and Justification for Dimensional Assessment of Symptoms and Related Clinical Phenomena in Psychosis: Relevance to DSM-5. Schizophrenia Research, 150, 15-20. https://doi.org/10.1016/j.schres.2013.04.027

Bermejo Saiz, B., Perez Urdániz, A., \& Santos, J. M. (2012). Mitos y delirios: Una reivindicación de Sarró. Actas Españolas de Psiquiatria, 40, 119-125.

Berrios, G. E. (1989). What Is Phenomenology? A Review. Journal of the Royal Society of Medicine, 82, 425-428. https://doi.org/10.1177/014107688908200718

Berríos, G. E. (2011). Psiquiatría y sus objetos. Revista de Psiquiatria Y Salud Mental, 4, 179-182. https://doi.org/10.1016/j.rpsm.2011.09.001

Crocq, M. A. (2015). A History of Anxiety: From Hippocrates to DSM. Dialogues in Clinical Neuroscience, 17, 319-325.

De Leon, J. (2013). Is Psychiatry Scientific? A Letter to a 21st Century Psychiatry Resident. Psychiatry Investigation, 10, 205-217. https://doi.org/10.4306/pi.2013.10.3.205

De Leon, J. (2014). ¿Es hora de despertar a la Bella Durmiente? En 1980, la psiquiatría europea cayó en un profundo sueño. Revista de Psiquiatria Y Salud Mental, 7, 186-194. https://doi.org/10.1016/j.rpsm.2013.12.004 
De Leon, J. (2015). Is Psychiatry Only Neurology? Or Only Abnormal Psychology? Déjà vu after 100 Years. Acta Neuropsychiatrica, 27, 69-81. https://doi.org/10.1017/neu.2014.34

Dramisino, H. (2013). Validity of the Existentialist Approach in Psychiatry. Vertex (Buenos Aires, Argentina), 24, 169-173. http://europepmc.org/abstract/MED/24255898

Fornaro, M., Clementi, N., \& Fornaro, P. (2009). Medicine and Psychiatry in Western culture: Ancient Greek Myths and Modern Prejudices. Annals of General Psychiatry, 8 , 21. https://doi.org/10.1186/1744-859X-8-21

Gustavo Figueroa, C. (2014). Freud, Breuer y Aristóteles: Catarsis y el descubrimiento del Edipo. Revista Chilena de Neuro-Psiquiatria, 52, 264-273. https://doi.org/10.4067/S0717-92272014000400004

Hipócrates (1999). De morbo sacro o El tratado de la epilepsia. Madrid: PARKE-DAVIS.

Hueso Holgado, H., \& Cuervo Díaz, F. (2013). Saber objetivo sobre la subjetividad en psiquiatría, desde la filosofía y el psicoanálisis. TT-Objective Knowledge about Subjectivity in Psychiatry, from Philosophy and Psychoanalysis. Revista de la Asociación Española de Neuropsiquiatría, 33, 273-287.

https://doi.org/10.4321/S0211-57352013000200004

Ivanovic-Zuvic, F. (2004). Consideraciones epistemológicas sobre la medicina y las enfermedades mentales en la antigua Grecia. Revista chilena de neuro-psiquiatría, 42, 163-175. https://doi.org/10.4067/S0717-92272004000300002

Jaspers, K. (1913). Allgemeine Psychopathologie. Berlin: Springer.

Kirk, G., \& Raven, J. (1981). Los Filósofos Presocráticos. Madrid: Gredos.

La Croce, E. (1981). Concept of Insanity in Classical Greece. Acta Psiquiatrica y Psicologica de America Latina, 27, 285-291.

Lear, J. (2014). Wisdom Won from Illness: The Psychoanalytic Grasp of Human Being. International Journal of Psychoanalysis, 95, 677-693. https://doi.org/10.1111/1745-8315.12209

Lyketsos, G. (1980). The Ancient Greek Tragedy as a Means of Psychotherapy for Mental Patients. Psychotherapy and Psychosomatics, 34, 241-247. https://doi.org/10.1159/000287464

Mason, E. (2015). Moral Ignorance and Blameworthiness. Philosophical Studies, 172, 3037-3057. https://doi.org/10.1007/s11098-015-0456-7

McHugh, P., \& Slavney, P. (2001). Las perspectivas de la psiquiatría (2nd ed.). Zaragoza: Prensas Universitarias de Zaragoza.

Mezzich, J. E. (2007). Psychiatry for the Person: Articulating Medicine's Science and Humanism. World Psychiatry: Official Journal of the World Psychiatric Association, 6, 65-67.

Muñoz Negro, J. E., Ibáñez-Casas, I., De Portugal, E., \& Cervilla Ballesteros, J. (2015). A Dimensional Redefinition of the Schizophrenia Spectrum: Delusional Disorder versus Schizophrenia versus Schizoaffective Disorder. European Psychiatry, 30, 898. https://doi.org/10.1016/S0924-9338(15)31962-3

Novais, F., Araújo, A., \& Godinho, P. (2015). Historical Roots of Histrionic Personality Disorder. Frontiers in Psychology, 6, 1463. https://doi.org/10.3389/fpsyg.2015.01463

Pichot, P. (1978). Hippocrate, Aristote, Galien et la Psychiatrie Antique. Neurologie-Psychiatrie, 22, 3-10.

Pies, R. (2007). The Historical Roots of the "Bipolar Spectrum": Did Aristotle Anticipate Kraepelin's Broad Concept of Manic-Depression? Journal of Affective Disorders, 100, 
7-11. https://doi.org/10.1016/j.jad.2006.08.034

Platón (2003). Diálogos. Obra completa en 9 volúmenes. Gredos: Fedón, Banquete, \& Fedro, Eds.

Szasz, T. (1961). The Myth of Mental Illness: Foundations of a Theory of Personal Conduct. New York, NY: Harper \& Row.

Turri, M. G. (2015). Transference and Katharsis, Freud to Aristotle. International Journal of Psychoanalysis, 96, 369-387. https://doi.org/10.1111/1745-8315.12243

Tzeferakos, G., \& Douzenis, A. (2014). Sacred Psychiatry in Ancient Greece. Annals of General Psychiatry, 13, 1-9. https://doi.org/10.1186/1744-859X-13-11

Van Os, J. (2012). Las soluciones para los pacientes dependen de que podamos salvar la distancia que separa los enfoques de investigación de ciencias sociales y ciencias naturales en el campo de la salud mental. Revista de Psiquiatría Y Salud Mental, 5, 135-138. https://doi.org/10.1016/j.rpsm.2012.05.002

Van Os, J., Hanssen, M., Bijl, R. V., \& Ravelli, A. (2000). Strauss (1969) Revisited: A Psychosis Continuum in the General Population? Schizophrenia Research, 45, 11-20. https://doi.org/10.1016/S0920-9964(99)00224-8 